\title{
INTENSIDADE TECNOLÓGICA DAS EXPORTAÇÕES DO BRASIL E DE ESTADOS SELECIONADOS (2000-2010)
}

\author{
BRAZIL AND ITS MAIN STATES TECHNOLOGICAL \\ INTENSITY OF EXPORTS (2000-2010)
}

\author{
Data de submissão: 08-10-2012 \\ Aceite: $16-10-2013$ \\ Gabriel Vogel ${ }^{1}$ \\ André Filipe Zago Azevedo²
}

\section{RESUMO}

Há um grande debate atualmente sobre o processo de reprimarização da pauta exportadora brasileira e de seus efeitos sobre a economia do país. Diante disso, este artigo tem por objetivo contribuir para essa discussão, buscando identificar a evolução do perfil de intensidade tecnológica das exportações brasileiras e dos principais estados exportadores, entre 2000 e 2010, para seus principais mercados. O estudo baseou-se em dados secundários quantitativos e oficiais, disponibilizados pelo Ministério do Desenvolvimento, Indústria e Comércio Exterior (MDIC). Os resultados apontam que, ao longo do período analisado, apesar do aumento das exportações totais, manteve-se a queda da participação de produtos com alta e média-alta intensidade tecnológica na pauta total de exportações, concentrando-se em produtos de baixa intensidade ou produtos primários, o que corrobora a permanência da hipótese de reprimarização da pauta exportadora brasileira, verificada na década de 1990. Tal situação também foi observada em todos os estados selecionados. Em relação ao destino das exportações dos estados, observou-se uma elevada participação de produtos de baixa intensidade tecnológica e commodities para a China, ao passo que o Mercosul manteve a maior participação de mercadorias de média-alta e média-baixa intensidade tecnológica.

Palavras-chave: Intensidade Tecnológica; Reprimarização das exportações; Competitividade.

\footnotetext{
${ }^{1}$ Possui graduação em Ciências Econômicas pela Universidade do Vale do Rio dos Sinos - UNISINOS. Novo Hamburgo. Rio Grande do Sul. Brasil. E-mail: gvogui@gmail.com

${ }^{2}$ Possui graduação em Economia pela Universidade Federal do Rio Grande do Sul - UFRGS, mestrado em Economia pela Universidade Federal do Rio Grande do Sul e Doutorado em Economia pela University of Sussex - SUSSEX, Inglaterra. Atualmente é professor na Universidade do Vale do Rio dos Sinos, UNISINOS. São Leopoldo. Rio Grande do Sul. Brasil. E-mail: aazevedo@unisinos.br
} 


\begin{abstract}
Nowadays, there is an intense debate about the process of reprimarization of Brazilian exports and its effects on the economy. This paper aims at contributing to this debate, aiming at identifying the technological intensity of Brazilian and its main states exports, between 2000 and 2010, to its main destinations. The study is based on secondary and official data, provided by the Ministry of Development, Industry and Foreign Trade (MDIC). The results show that in this period, despite the increase in total exports, there was a drop in the share of high and medium-high technological intensity products on total exports, with a concentration of exports on low technological intensity and primary products, corroborating the hypothesis of the continuation of reprimarization of exports, observed originally in de 1990s. This situation was also observed in all main export states. With regard the states export destination, there was a high share of commodities and low intensity products in total exports to China, while Mercosur showed a higher concentration on medium-high and high technological products.
\end{abstract}

Keywords: Technological intensity; Reprimarization of exports, Competitiveness.

\title{
1 INTRODUÇÃO
}

A literatura aponta uma série de benefícios decorrentes da incorporação de tecnologia aos produtos de exportação de um país, com destaque para a maior agregação de valor aos produtos, bem como a ampliação do dinamismo de suas exportações. Furtado (1994) indica que a capacitação tecnológica é responsável por permitir a existência de vantagens comparativas dinâmicas, fundamentais em um cenário de globalização e, portanto, de acirrada concorrência internacional. Markwald (2004) destaca que as firmas mais intensivas em tecnologia seriam mais inovadoras e mais eficientes, pagariam salários mais altos e seriam mais bem-sucedidas na ampliação de seus mercados.

Com a abertura comercial acentuada, a partir da década de 1990, a indústria brasileira teve a tarefa de incorporar o progresso tecnológico, a fim de alavancar sua produtividade e competitividade. Gonçalves (2001), baseando-se nas exportações brasileiras da década de 1990, identificou um processo contrário ao desejado: entre 1990 e 1999, o Brasil reduziu a participação de produtos com maior conteúdo tecnológico e aumentou a participação de itens primários, caracterizando um processo de reprimarização da pauta exportadora ${ }^{3}$. Assim, este artigo visa identificar a intensidade tecnológica das exportações do Brasil, entre 2000 e 2010, e examinar se houve a manutenção do processo de reprimarização. Também são avaliadas as pautas exportadoras dos principais estados exportadores, isto é Rio Grande do Sul (RS), São Paulo (SP), Rio de Janeiro (RJ) e Minas Gerais (MG), para identificar se essa tendência também está presente nesses estados e se há um perfil similar das exportações para os seus principais destinos.

Além desta introdução, o artigo apresenta mais quatro seções. Na segunda seção, é apresentada a metodologia para a classificação da intensidade tecnológica dos produtos, bem como as fontes dos dados. A terceira seção faz uma breve revisão de literatura sobre os benefícios da maior intensidade tecnológica das exportações e examina a evolução das exportações brasileiras e dos principais estados, entre 2000 e 2010. A quarta seção, por sua vez, apresenta a evolução do perfil tecnológico das exportações brasileiras e dos estados, ao longo do período analisado, com ênfase nos seus principais destinos, incluindo Estados Unidos, União Europeia, China e Mercosul. Por fim, a última seção aponta as conclusões.

${ }^{3} \mathrm{~A}$ expressão "reprimarização das exportações" indica o retorno de uma pauta exportadora baseada, predominantemente, em produtos primários ou agrícolas, situação verificada ao Brasil até a metade do século XX. 


\section{METODOLOGIA}

Este artigo busca identificar a evolução do perfil tecnológico das exportações brasileiras e dos principais estados exportadores, no período de 2000 a 2010, baseando-se em dados secundários quantitativos e oficiais, disponibilizados pelo Ministério do Desenvolvimento, Indústria e Comércio Exterior (MDIC). O exame da intensidade tecnológica dos produtos seguiu a proposta da Organisation for Economic Cooperation and Development (OECD), órgão responsável pela publicação do International Standard Industrial Classification of All Economic Activities (ISIC), que atribui ao código de classificação das empresas e indústrias um determinado nível de intensidade tecnológica. Este artigo adota a revisão 3, publicada em $2003^{4}$. Essa publicação determina que a identificação de setores de alta tecnologia e média-alta tecnologia parte da intensidade de gastos com P\&D, enquanto que, para os níveis de média-baixa tecnologia e baixa tecnologia, são avaliadas a intensidade de capital e trabalho. Portanto, atribui aos setores os quatro possíveis níveis de intensidade tecnológica descritos a seguir:

alta intensidade tecnológica - indústrias aeroespaciais, farmacêuticas, de equipamentos ópticos e de precisão para medicina, de tecnologia e informação e de telecomunicações;

média-alta intensidade tecnológica - indústrias automobilísticas e de transporte em geral, de outros equipamentos elétricos, químicas, exceto farmacêuticas, ferroviárias, de outros equipamentos e maquinários;

média-baixa intensidade tecnológica - indústrias navais, de borracha e plásticos, de produtos refinados do petróleo e de combustíveis nucleares, de produtos minerais não metálicos, de metalurgia básica e de produtos metálicos;

baixa intensidade tecnológica - demais indústrias manufatureiras, de reciclagem, de madeira, celulose, papel, impressão e publicação, alimentícias, de bebidas e fumo, têxteis, de produtos de confecção, couro e calçados.

A comparação da Nomenclatura Comum do Mercosul (NCM) com a ISIC foi possível pela correspondência que o Instituto Brasileiro de Geografia e Estatística (IBGE) possui em seu sítio na internet ${ }^{5}$, atribuindo a uma NCM um Código Nacional de Atividades Econômicas (CNAE Versão 1.0), que permite classificar a NCM quanto ao nível de intensidade tecnológica de acordo com a ISIC.

Os dados relativos ao Brasil e aos estados foram selecionados a partir da base do Sistema de Análise das Informações de Comércio Exterior via Internet versão 2 (AliceWeb2), do MDIC6. Embora houvesse disponibilidade de dados com oito dígitos da NCM, os dados foram restritos a quatro dígitos do Sistema Harmonizado (SH4), limitação que almeja evitar as distorções provenientes das alterações na Tarifa Externa Comum (TEC), durante o período de 2000 a 2010, em especial as ocorridas em 2002 e $2007^{7}$. Entretanto, como em um mesmo capítulo da TEC pode haver produtos com diferentes intensidades tecnológicas, foi necessário estabelecer um padrão para toda a pesquisa, com a adoção de um nível de intensidade tecnológica para determinada posição SH4. Para tal finalidade, foram consultadas as exportações totais, entre os períodos de 2000 a 2010, com oito dígitos da NCM, sendo a correspondência de intensidade tecnológica determinada de acordo com os produtos que detiveram os maiores volumes de exportações ${ }^{8}$, tanto a nível nacional quanto estatal.

\footnotetext{
${ }^{4}$ OECD. STAN Indicators, 2003.

${ }^{5}$ IBGE. Classificações estatísticas e a comissão nacional de classificação (CONCLA). Tabelas de Correspondência.

${ }^{6}$ As pesquisas na base de dados do AliceWeb2 indicam as posições SH4 de código 9991, 9997, 9998 e 9999 , as quais não possuem descrição de produtos de acordo com a TEC (a base de dados classifica-as como "NÃO DEFINIDO"), sendo, portanto, desconsideradas quanto à classificação da intensidade tecnológica.

${ }^{7}$ FEE - Fundação de Economia e Estatística, Nota Metodológica - e MDIC - Resolução CAMEX 43, de 22/12/2006.

${ }^{8}$ Exemplificando: os tabacos, quando transformados em charutos ou cigarros, são apontados pela ISIC revisão 3 como de baixa intensidade tecnológica, mas, na forma bruta, são produtos primários. As exportações de tabacos do RS, entre 2000 e 2010 , foram classificadas como produtos primários, já que a maior parte das exportações foi de fumo em folhas, na forma bruta, sem processamento ou sem transformação.
} 


\section{REVISÃO DE LITERATURA}

A literatura aponta que a incorporação de tecnologia ao produto é condição desejável aos países que buscam agregar valor aos produtos, bem como ampliar o dinamismo de suas exportações. Furtado (1994), por exemplo, indica que a capacitação tecnológica é responsável por permitir a existência de vantagens comparativas dinâmicas, destaque em um cenário de globalização e, portanto, de acirrada concorrência internacional. Markwald (2004, p. 4) explicita que as "[...] firmas intensivas em tecnologia são mais inovadoras, utilizam seus recursos produtivos de maneira mais eficiente, pagam salários mais elevados e são mais bem sucedidas no objetivo de ampliar seus mercados" ${ }^{\prime 9}$. Portanto, em um ambiente econômico caracterizado por uma grande competição entre empresas em nível global, a busca pela inovação de produtos e processos tornou-se um grande diferencial competitivo das empresas.

Furtado e Carvalho (2005) também ressaltam a importância de setores intensivos em tecnologia, apontando que as economias desenvolvidas possuem diferenciações quanto à especialização de sua produção, devido aos diversos setores intensivos em alta e média tecnologia, e que, quanto maior a presença desses setores, maior é a solidez da indústria local.

Gonçalves (2001), Erber (2001), Belluzzo (2002), Coutinho et al. (2003), Markwald (2004), Bender (2006) e Pereira et al. (2007) apontam em seus estudos que a década de 1990 e os primeiros anos de 2000 foram de inserção internacional regressiva para o Brasil, fundamentada na competitividade de produtos classificados como primários ou de baixa intensidade tecnológica, em detrimento da queda de participação dos produtos de maior conteúdo tecnológico. Gonçalves (2001) ressalta, ainda, que o desempenho das exportações das indústrias brasileiras, na década de 1990, configurou-se pela reprimarização após a abertura comercial.

Ribeiro (2009) salienta, no entanto, que tal fenômeno não é, necessariamente, um processo negativo, na medida em que o país tem uma variada gama de produtos primários que compõem a sua pauta exportadora, diferentemente de outros países baseados em apenas um ou poucos produtos. Além disso, o Brasil detém nítidas vantagens comparativas em várias commodities, sendo natural a especialização da produção em produtos primários. Nessa mesma linha, Lall (2000) afirma que a tecnologia não desempenha papel relevante nas exportações dos países em desenvolvimento, para os quais o principal fator de competitividade continua sendo a dotação de fatores.

Contudo, a permanência desse cenário pode, eventualmente, induzir a um processo de desindustrialização ${ }^{10}$, processo já identificado por Cruz et al. (2007), Marconi (2008), Carvalho e Silva (2008), Oreiro e Feijó (2010) e Soares et al. (2011) e citado como consequência, em longo prazo, por Nassif (2008) e Fligenspan et al. (2011), caso mantida a apreciação cambial que reduz a competitividade da indústria brasileira.

Apesar dos cenários vivenciados pelo Brasil no final da década de 1990 - com as crises dos países asiáticos, da Rússia e da Argentina, sendo este importante parceiro comercial -, durante os anos de 2000 a 2008, coube ao Brasil aproveitar o cenário internacional de relativo crescimento das economias mundiais e, portanto, de elevação das trocas internacionais, resultando em saldos

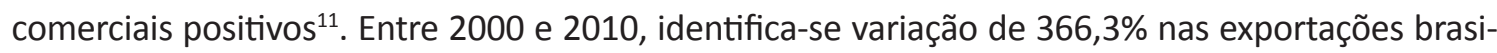
leiras, as quais, de 2000 até 2002, mantiveram-se relativamente estáveis, entre US\$ 55 e US\$ 60 bilhões, mostrando significativo crescimento desde então até 2008 , mesmo com a forte valorização cambial ocorrida a partir de 2004. Em 2008, com a deflagração da crise financeira internacional,

\footnotetext{
${ }^{9}$ Fernandéz-Járdon (2012), Silveira et al. (2012) e Denardin et al. (2012) apresentam exemplos regionais e setoriais que mostram a importância da inovação para o desenvolvimento produtivo de uma região.

${ }^{10}$ Conforme Rowthorn e Ramaswany (1999 apud OREIRO; FEIJÓ, 2010, p. 220), a desindustrialização ocorre em um cenário de "[...] redução persistente da participação do emprego industrial no emprego total de um país ou região".

${ }^{11}$ WTO. World Trade Organization.International Trade Statistics 2011. Appendix: Historical trends.
} 
houve retração do comércio mundial, efeito percebido no Brasil, que reduzira as exportações de US\$197,9 bilhões, em 2008, para US\$ 153 bilhões, em 2009, retomando, porém, seu crescimento em 2010, o qual teve variação positiva de 31,97\%, chegando a US\$201,9 bilhões.

Em relação às exportações dos principais estados brasileiros, conforme ilustrado no Gráfico 1, o Rio Grande do Sul exportou US\$ 5,78 bilhões, em 2000, e US\$ 15,38 bilhões, em 2010, representando variação de $265,99 \%$ no período. São Paulo, por sua vez, exportou US\$ 19,81 bilhões, em 2000, e US\$ 52,29 bilhões, em 2010, mostrando variação de $263,97 \%$. 0 estado de Minas Gerais exportou US\$ 6,71 bilhões, em 2000, e US\$31,22 bilhões, em 2010, conferindo acréscimo de $465,2 \%$ no período. Por fim, o Rio de Janeiro destacou-se com a maior variação no período dentre os estados analisados - 1.088,10\% -, passando de US\$1,84 bilhão, em 2000, para US\$20,02 bilhões, em 2010. De maneira assemelhada ao comportamento das exportações brasileiras, os estados apresentaram crescimento positivo (com exceção de SP que, entre 2001 e 2002, teve queda de 2,46\% e MG que, entre 2001 e 2002, retraiu suas exportações em 9,72\%) até 2009, quando houve retração em todos os estados analisados. Portanto, nesta década, apenas Minas Gerais e Rio de Janeiro tiveram crescimento de suas exportações acima da média brasileira.

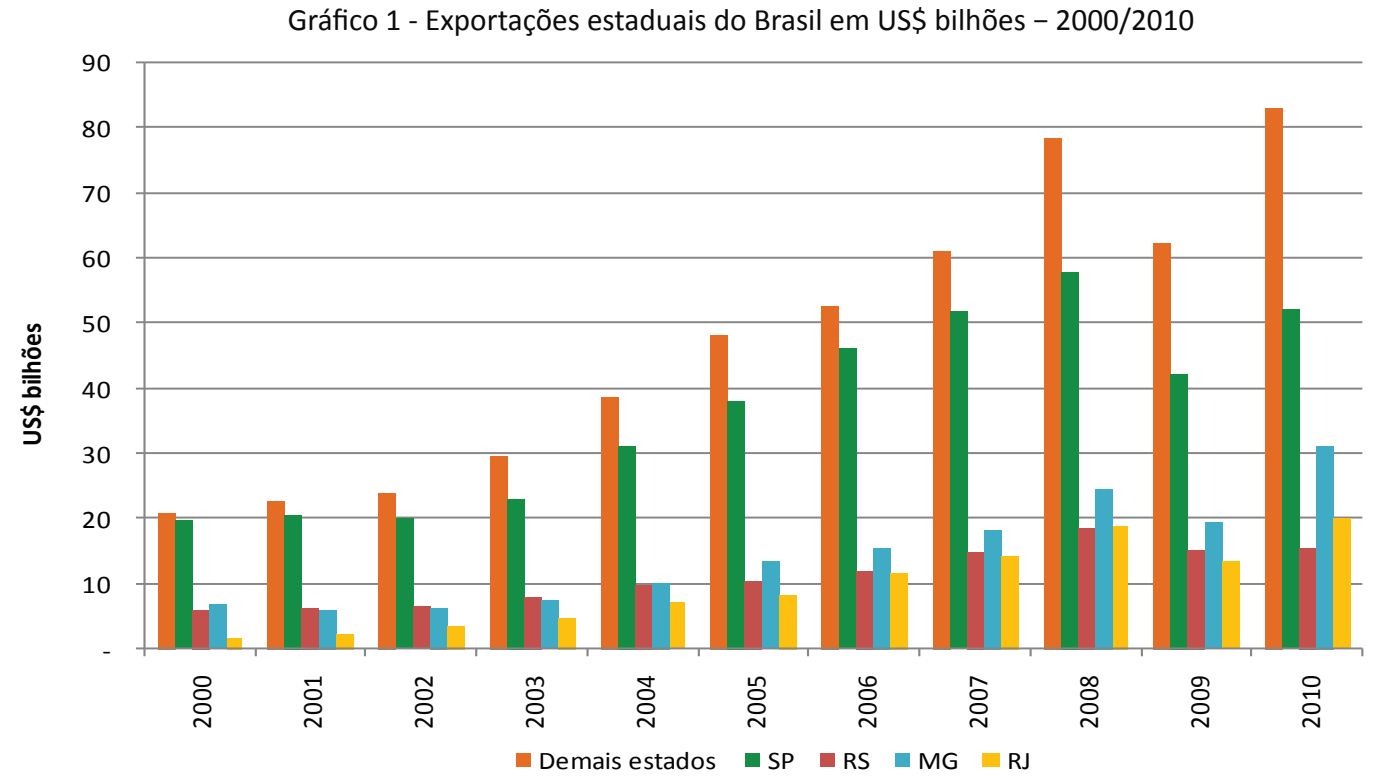

Fonte de dados: MDIC/AliceWeb2. Elaboração dos autores.

Procedendo à avaliação da participação de cada estado na pauta exportadora brasileira, - Gráfico 2 indica que tanto São Paulo quanto o Rio Grande do Sul diminuíram suas participações no total das exportações do Brasil. No início do período, o Rio Grande do Sul contribuía com $10,5 \%$ do total das exportações, ao passo que, em 2010 , reduziu essa contribuição para 7,6\%, havendo uma queda de 2,9 pontos percentuais. Em situação similar, São Paulo, que concentrava participação de 35,9\%, em 2000, reduziu sua participação para 25,9\%, com uma queda de 10 pontos percentuais ao final do período. Nos estados de Minas Gerais e Rio de Janeiro, percebe-se um aumento na participação das exportações do Brasil: Minas Gerais compunha 12,2\% das exportações brasileiras, em 2000, e respondia por $15,5 \%$, em 2010, com uma variação de 3,3 pontos percentuais; o Rio de Janeiro, como reflexo do aumento de suas exportações em 1.088,10\% no período, ampliou sua participação de 3,3\%, em 2000, para 9,9\%\%, em 2010. 
Gráfico 2 - Participação dos estados brasileiros nas exportações totais do Brasil em \% - 2000/2010

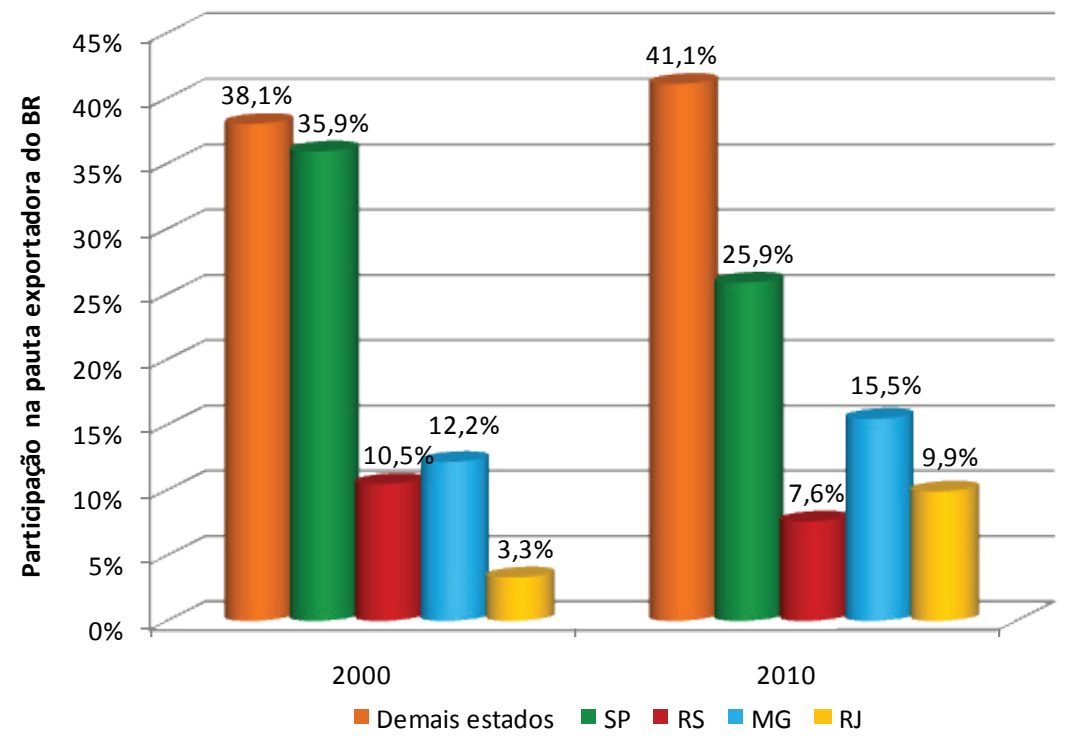

Fonte de dados: MDIC/AliceWeb2. Elaboração dos autores.

\subsection{Destinações das exportações do Brasil e dos estados selecionados}

Durante o período avaliado, as exportações brasileiras mostraram forte alteração em relação a seus destinos. Conforme indica a Tabela 1, o Mercosul, os Estados Unidos (EUA), a União Europeia (UE) e a China foram responsáveis por receberem 66,7\% das exportações do Brasil, em 2000, havendo uma suave redução do grau de concentração, em 2010, passando a 58,3\% das exportações, apesar do aumento considerável das exportações para esses mercados no período, que chegou a $366,3 \%$. Chama a atenção que, para esses quatro principais destinos das exportações brasileiras, somente houve aumento da participação na pauta total da China. As exportações para a UE, para a qual o Brasil exportara $27,0 \%$ do total das mercadorias, em 2000 , tiveram aumento, em termos absolutos, mas apresentaram menor participação na pauta exportadora (21,0\%), em 2010. Por sua vez, a China recebia apenas 3,4\% de todas as exportações do país, em 2000, e 16,9\%, em 2010, com forte incremento em termos absolutos (1.705,5\% no período). Se a China se destacava pela variação positiva, os EUA encontravam-se em situação inversa, com redução de 13,1 pontos percentuais no período, respondendo por 22,4\% das exportações, em 2000, e por apenas 9,3\%, em 2010.

Tabela 1 - Exportações totais para destinos selecionados em US\$ e \% - Brasil - 2000/2010

\begin{tabular}{|c|c|c|c|c|c|c|}
\hline \multirow[t]{2}{*}{ DESTINO } & \multicolumn{2}{|c|}{2000} & \multicolumn{2}{|l|}{2010} & \multicolumn{2}{|c|}{ No período } \\
\hline & Valores em US\$ & $\begin{array}{l}\text { Particip. nas } \\
\text { exportações } \\
\text { totais em \% }\end{array}$ & Valores em US\$ & $\begin{array}{l}\text { Particip. nas } \\
\text { exportações } \\
\text { totais em \% }\end{array}$ & $\begin{array}{c}\text { Variação } \\
\text { valores } \\
\text { US\$ em \% }\end{array}$ & $\begin{array}{c}\text { Variação } \\
\text { particip. } \\
\text { em p.p. }\end{array}$ \\
\hline (A) MERCOSUL & 7.624.924.087,00 & 13,8 & $22.292 .998 .788,00$ & 11,0 & 192,4 & $-2,8$ \\
\hline (B) ESTADOS UNIDOS & $12.350 .171 .751,00$ & 22,4 & $18.761 .955 .590,00$ & 9,3 & 51,9 & $-13,1$ \\
\hline (C) UNIÃO EUROPEIA & $14.888 .815 .723,00$ & 27,0 & $42.459 .001 .238,00$ & 21,0 & 185,2 & $-6,0$ \\
\hline (D) CHINA* & $1.889 .953 .462,00$ & 3,4 & $34.122 .978 .826,00$ & 16,9 & $1.705,5$ & 13,5 \\
\hline Subtotal $(A+B+C+D)$ & $36.753 .865 .023,00$ & 66,7 & $117.636 .934 .442,00$ & 58,3 & 220,1 & $-8,4$ \\
\hline Exportações totais & $55.118 .919 .865,00$ & & $201.915 .285 .335,00$ & & & \\
\hline
\end{tabular}

* incluindo HK, Macau e Taiwan

Fonte de dados brutos: MDIC/AliceWeb2. Elaboração dos autores. 
No caso do Mercosul, a queda foi menor, de 2,8 pontos percentuais, passando para $11,0 \%$ do total exportado pelo Brasil, em 2010. Uma vez que os estados exportadores selecionados, em conjunto, atingem mais de $50 \%$ da pauta exportadora brasileira, como destacado no Gráfico 2, faz-se pertinente analisá-los a fim de perceber sua influência para o desempenho do agregado brasileiro.

\section{RESULTADOS}

\subsection{Resultados da variação da intensidade tecnológica no Brasil}

A variação da participação de cada nível de intensidade tecnológica, na pauta exportadora, resulta da relação entre o total exportado em cada categoria e o montante total exportado pelo Brasil ou cada um dos estados. Markwald (2004), em sua análise para o Brasil, atribuiu a estagnação e a queda das exportações de alta tecnologia, de 2000 a 2003, não somente à ascensão dos produtos primários no total, mas também à queda das vendas externas das indústrias e dos setores de maior intensidade tecnológica.

Visto que o volume de exportação de cada intensidade tecnológica pode afetar a relação, contribuindo, então, para a queda destes produtos no total exportado, fez-se necessário confirmar a variação em valores brutos das destinações do Brasil e dos estados selecionados. Conforme consta no Gráfico 3, todas as categorias de tecnologia tiveram desempenho positivo, entre 2000 e 2010, sendo o setor de alta tecnologia o de menor variação (32\%), seguido pelos produtos de média-baixa tecnologia (179\%). Em seguida, apareceram os produtos de média-alta tecnologia, com elevação de $186 \%$, enquanto os produtos classificados como de baixa intensidade tecnológica mostravam variação de $232 \%$. Por último, há os produtos primários (commodities), que alcançaram a maior variação, chegando a 747\%, entre 2000 e 2010. Logo, percebe-se que a participação de produtos de alta intensidade não se reduziu por declínio das exportações do setor, em termos absolutos, mas pela significativa variação dos produtos de baixa intensidade tecnológica e produtos primários.

Gráfico 3 - Exportações totais em US\$ bilhões, por intensidade tecnológica - Brasil - 2000/2010

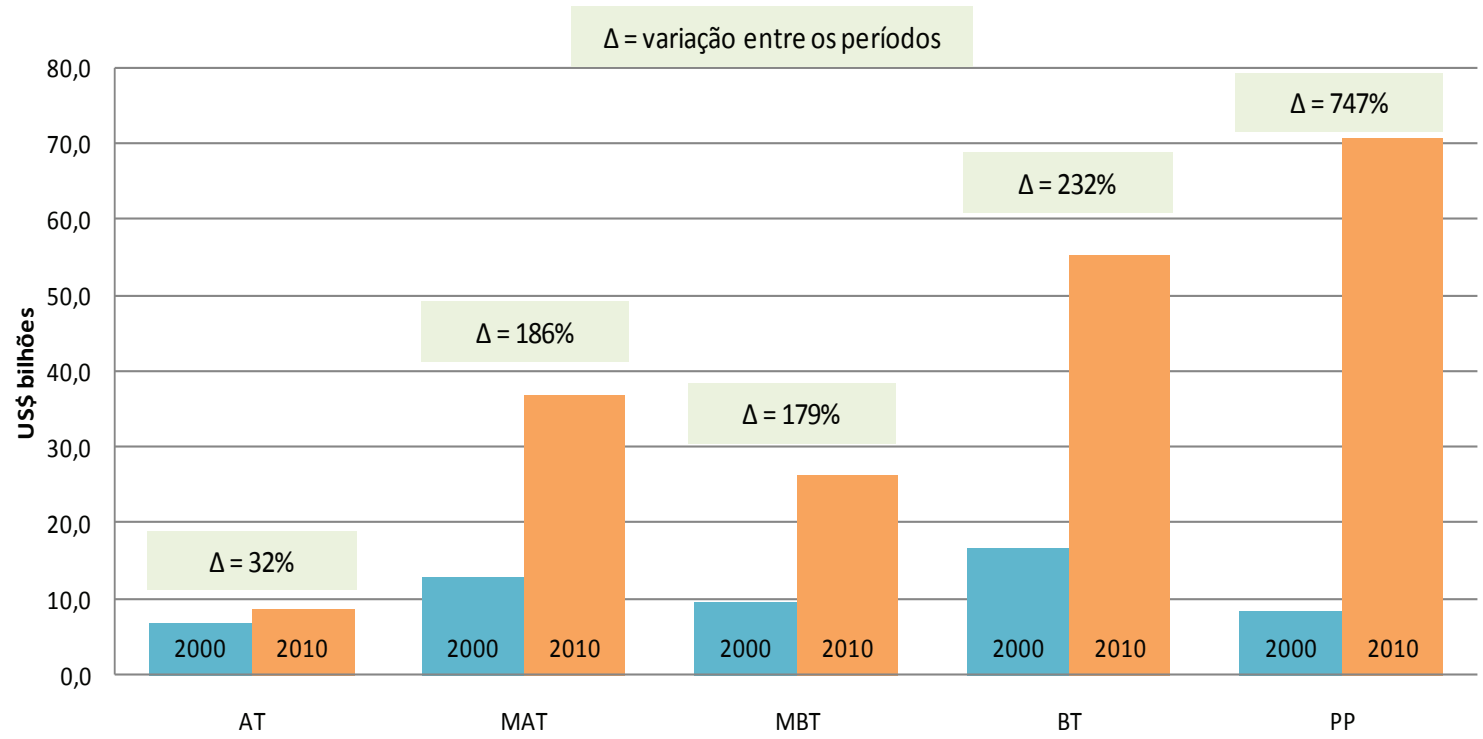

AT = Alta Tecnologia; MAT = Média-alta Tecnologia; MBT = Média-baixa Tecnologia; $\mathrm{BT}=$ Baixa Tecnologia; $\mathrm{PP}=$ Produtos Primários Fonte: Exportações de MDIC/AliceWeb2. Intensidade tecnológica conforme OECD/ISIC revisão 3. Elaboração dos autores. 
Em relação aos estados, como destacado na Tabela 2, todos apresentaram variação positiva, em termos absolutos, em cada uma das intensidades tecnológicas. Na categoria de alta intensidade tecnológica, São Paulo era o principal exportador, em termos de valor, em ambos os períodos, e Minas Gerais, embora com volume muito menor que São Paulo, fora o estado que conquistara maior variação nesta categoria (302\%) entre 2000 e 2010. São Paulo detinha os maiores valores em ambos os períodos quanto às mercadorias de média-alta e média-baixa intensidade tecnológica, apenas ultrapassado por Minas Gerais, em 2010, nesta última classificação. Nos anos de 2000 a 2010, o Rio Grande do Sul tinha os maiores destaques, em termos absolutos, na categoria de média -baixa intensidade e nos produtos primários, cada um com $292 \%$ de variação, ao passo que o estado paulista teve maiores variações nos itens de baixa tecnologia (288\%) e primários (200\%). O Rio de Janeiro incrementou as exportações dos produtos primários (8.955\%) e de média-alta intensidade (327\%), enquanto que Minas Gerais apresentava variação, principalmente, nos produtos primários (558\%), sucedidos por produtos de baixa intensidade tecnológica (362\%).

Tabela 2 - Exportações totais dos estados brasileiros, em US\$ bilhões, por intensidade tecnológica - 2000/2010

\begin{tabular}{|c|c|c|c|c|c|c|c|c|c|c|c|c|}
\hline \multirow[t]{3}{*}{$\begin{array}{c}\text { Grau de } \\
\text { intensidade } \\
\text { tecnológica }\end{array}$} & \multicolumn{2}{|c|}{$\begin{array}{l}\text { Valores em } \\
\text { US\$ bilhões }\end{array}$} & \multirow[t]{2}{*}{$\begin{array}{c}\text { Variação } \\
\text { em \% }\end{array}$} & \multicolumn{2}{|c|}{$\begin{array}{l}\text { Valores em } \\
\text { US\$ bilhões }\end{array}$} & \multirow[t]{2}{*}{$\begin{array}{c}\text { Variação } \\
\text { em \% }\end{array}$} & \multicolumn{2}{|c|}{$\begin{array}{l}\text { Valores em } \\
\text { US\$ bilhões }\end{array}$} & \multirow[t]{2}{*}{$\begin{array}{c}\text { Variação } \\
\text { em \% }\end{array}$} & \multicolumn{2}{|c|}{$\begin{array}{l}\text { Valores em } \\
\text { US\$ bilhões }\end{array}$} & \multirow[t]{2}{*}{$\begin{array}{c}\text { Variação } \\
\text { em \% }\end{array}$} \\
\hline & & RS & & & SP & & & RJ & & & MG & \\
\hline & 2000 & 2010 & $\begin{array}{c}\text { No } \\
\text { período }\end{array}$ & 2000 & 2010 & $\begin{array}{c}\text { No } \\
\text { período }\end{array}$ & 2000 & 2010 & $\begin{array}{c}\text { No } \\
\text { período }\end{array}$ & 2000 & 2010 & $\begin{array}{c}\text { No } \\
\text { período }\end{array}$ \\
\hline Alta & 0,07 & 0,15 & 124 & 4,84 & 6,42 & 33 & 0,15 & 0,23 & 57 & 0,08 & 0,30 & 302 \\
\hline Média-alta & 1,45 & 4,06 & 180 & 6,84 & 19,22 & 181 & 0,37 & 1,60 & 327 & 1,21 & 2,98 & 146 \\
\hline Média-baixa & 0,29 & 1,14 & 292 & 2,59 & 5,52 & 113 & 0,78 & 2,31 & 198 & 1,94 & 6,37 & 228 \\
\hline Baixa & 2,91 & 6,02 & 107 & 4,71 & 18,27 & 288 & 0,15 & 0,19 & 31 & 0,69 & 3,20 & 362 \\
\hline Prod. Primários & 0,99 & 3,88 & 292 & 0,44 & 1,33 & 200 & 0,17 & 15,08 & 8.955 & 2,79 & 18,35 & 558 \\
\hline
\end{tabular}

Fonte: Exportações de MDIC/AliceWeb2. Intensidade tecnológica conforme OECD/ISIC revisão 3. Elaboração dos autores.

Uma vez que a queda das vendas, em termos absolutos, não se confirmou entre 2000 e 2010, é importante examinar a participação relativa de cada categoria de tecnologia no total das exportações. Como indica a Tabela 3, no início do período avaliado, a pauta brasileira possuía 35,57\% de itens classificados como de alta ou média-alta intensidade tecnológica, enquanto que os itens classificados como de média-baixa ou baixa intensidade correspondiam a 47,29\% e os produtos primários (na forma bruta ou commodities) a apenas 15,18\%. Em 2010, houve redução da participação de mercadorias tanto de alta quanto de média-alta intensidade tecnológica, de 7,82 e 5,14 pontos percentuais, respectivamente. Esse resultado mostra que a tendência observada por Coutinho et al. (2003) - que, em estudo referente ao período de 1989 a 2002, identificou baixo desempenho nas exportações de alta e média intensidade tecnológica do Brasil -manteve-se no período mais recente. Conclusão semelhante é apontada por Bender (2006), que verificou ínfimo desempenho dos setores intensivos em tecnologia durante a década de 1990. Markwald (2004) percebeu queda, entre os anos de 2000 a 2003, nas exportações high-tech do Brasil, atribuindo o mal desempenho da categoria a um reflexo do declínio das vendas, principalmente, dos produtos aeroespaciais.

A variação mais significativa, entre os períodos estudados, ocorre nos produtos primários, ou commodities, que estavam no patamar de $15,18 \%$, em 2000 , e atingem $35,11 \%$, em 2010 , indicando um acréscimo de 19,93 pontos percentuais. Este resultado reforça a tendência de reprimarização da pauta exportadora brasileira, identificada por Gonçalves (2001) na década de 1990 e de uma inserção 
internacional baseada em exportações de commodities, conforme apontam Castilhos e Carneiro (2008).

No entanto, ao observar os principais estados exportadores, percebe-se que o desempenho foi diferenciado no que tange aos níveis de intensidade tecnológica. Conforme já mencionado, todos os estados selecionados tiveram contração nos percentuais de participação da alta intensidade tecnológica na pauta exportadora, entre 2000 e 2010, tendo São Paulo e Rio de Janeiro papel crucial para o cenário brasileiro, uma vez que, neste nível tecnológico, cederam 12,15 e 6,90 pontos percentuais, respectivamente. São Paulo apresentava exportações de produtos high-tech que chegavam a 12,27\% do total exportado, enquanto o Rio de Janeiro apresentava apenas 1,17\%, em 2010. O Rio Grande do Sul e Minas Gerais tinham ínfima participação em ambos os períodos: o estado gaúcho apresentava, em 2010, exportações de apenas 1,01\% de produtos de alta tecnologia; enquanto que o estado mineiro apresentava um índice de 0,97\%, logo, sem condições de interferir substancialmente na pauta exportadora brasileira.

A queda das exportações de média-alta intensidade do Brasil, com variação de menos 5,14 pontos percentuais, resultam, em boa parte, de quedas desta categoria em Minas Gerais e no Rio de Janeiro, com declínio de 8,49 e 12,38 pontos percentuais, respectivamente. Diferentemente do verificado no Brasil, no Rio de Janeiro e em Minas Gerais, os estados do Rio Grande do Sul e de São Paulo exibem pequeno incremento desses tipos de produtos no total das exportações estaduais.

As variações da participação dos itens de baixa intensidade tecnológica, que no agregado brasileiro caíram de 30,14\%, em 2000, para 27,34\%, em 2010, foram influenciadas pelo desempenho das exportações do Rio Grande do Sul, do Rio de Janeiro e de Minas Gerais; dentre os quais, o maior registro, nesta categoria, foi do Rio Grande do Sul, com queda de 11,25 pontos percentuais entre 2000 e 2010. Em contrapartida, São Paulo apresentou a maior elevação da participação dos produtos de baixa intensidade tecnológica em sua pauta (de 23,76\%, em 2000, para 34,94\% em 2010), sendo este talvez o motivo pelo qual não houve uma queda tão expressiva para o Brasil.

A elevação da participação dos produtos primários, que respondiam por 35,11\% das exportações do Brasil, em 2010, ante 15,18\%, identificados em 2000, resulta também da variação das exportações do Rio Grande do Sul, do Rio de Janeiro e de Minas Gerais, cuja categoria teve incremento na pauta exportadora destes estados de 8,11, 66,25 e 17,22 pontos percentuais, respectivamente, entre 2000 e 2010. Vale destacar dois comportamentos comuns para todos os estados e, portanto, para o Brasil: o de queda generalizada da participação dos produtos de alta intensidade tecnológica e de aumento das commodities.

Tabela 3 - Participação de cada nível de intensidade tecnológica, em \%, nas exportações totais do Brasil e dos estados selecionados $-2000 / 2010$

\begin{tabular}{|c|c|c|c|c|c|c|c|c|c|c|c|c|c|c|c|}
\hline \multirow[t]{3}{*}{$\begin{array}{c}\text { Grau de } \\
\text { intensidade } \\
\text { tecnológica }\end{array}$} & \multicolumn{2}{|c|}{$\begin{array}{c}\text { Participação } \\
\text { no total \% }\end{array}$} & \multirow[t]{2}{*}{$\begin{array}{l}\text { Variação } \\
\text { em p.p. }\end{array}$} & \multicolumn{2}{|c|}{$\begin{array}{c}\text { Participa ção } \\
\text { no total \% }\end{array}$} & \multirow[t]{2}{*}{$\begin{array}{c}\text { Variação } \\
\text { em p.p. }\end{array}$} & \multicolumn{2}{|c|}{$\begin{array}{c}\text { Participação } \\
\text { no total \% }\end{array}$} & \multirow[t]{2}{*}{$\begin{array}{c}\text { Variação } \\
\text { em p.p. }\end{array}$} & \multicolumn{2}{|c|}{$\begin{array}{c}\text { Participação } \\
\text { no total \% }\end{array}$} & \multirow[t]{2}{*}{$\begin{array}{c}\text { Variação } \\
\text { em p.p. }\end{array}$} & \multicolumn{2}{|c|}{$\begin{array}{c}\text { Participação } \\
\text { no total \% }\end{array}$} & \multirow{2}{*}{$\begin{array}{r}\text { Variaçãc } \\
\text { em p.p. }\end{array}$} \\
\hline & & $B R$ & & & RS & & & SP & & & RJ & & & MG & \\
\hline & 2000 & 2010 & $\begin{array}{c}\text { No } \\
\text { período }\end{array}$ & 2000 & 2010 & $\begin{array}{c}\text { No } \\
\text { período }\end{array}$ & 2000 & 2010 & $\begin{array}{c}\text { No } \\
\text { período }\end{array}$ & 2000 & 2010 & $\begin{array}{c}\text { No } \\
\text { período }\end{array}$ & 2000 & 2010 & $\begin{array}{c}\text { No } \\
\text { período }\end{array}$ \\
\hline Alta & 12,19 & 4,38 & $-7,82$ & 1,20 & 1,01 & $-0,19$ & 24,43 & 12,27 & $-12,15$ & 8,07 & 1,17 & $-6,90$ & 1,13 & 0,97 & $-0,15$ \\
\hline Média-alta & 23,38 & 18,24 & $-5,14$ & 25,12 & 26,42 & 1,30 & 34,55 & 36,75 & 2,20 & 20,38 & 7,99 & $-12,38$ & 18,03 & 9,53 & $-8,49$ \\
\hline Média-baixa & 17,15 & 13,06 & $-4,10$ & 5,03 & 7,42 & 2,39 & 13,09 & 10,56 & $-2,53$ & 42,18 & 11,56 & $-30,62$ & 28,97 & 20,41 & $-8,56$ \\
\hline Baixa & 30,14 & 27,34 & $-2,80$ & 50,38 & 39,13 & $-11,25$ & 23,76 & 34,94 & 11,18 & 7,90 & 0,95 & $-6,95$ & 10,31 & 10,25 & $-0,07$ \\
\hline Produtos Primários & 15,18 & 35,11 & 19,93 & 17,14 & 25,25 & 8,11 & 2,24 & 2,54 & 0,30 & 9,05 & 75,29 & 66,25 & 41,54 & 58,76 & 17,22 \\
\hline Outros (indefinidos) & 1,95 & 1,87 & $-0,08$ & 1,14 & 0,79 & $-0,36$ & 1,95 & 2,95 & 0,99 & 12,43 & 3,04 & $-9,39$ & 0,03 & 0,07 & 0,05 \\
\hline
\end{tabular}

Fonte: Exportações de MDIC/AliceWeb2. Intensidade tecnológica conforme OECD/ISIC revisão 3. Elaboração dos autores. 


\subsection{Intensidades tecnológicas das exportações estaduais conforme a destinação}

Em virtude do declínio da participação dos EUA e da UE nas exportações do Brasil, da ascensão da China e da confirmação de queda relativa das exportações de produtos com alta e média-alta intensidade tecnológica - com aumento das exportações de produtos de baixa intensidade tecnológica e produtos primários -, fez-se oportuno pesquisar a participação de cada categoria de intensidade tecnológica nas exportações dos estados para esses destinos em questão.

Apresentando-se como o fundamental nicho de destino das exportações brasileiras em 2000 e 2010, a UE teve importância distinta entre os estados. Como mostra a Tabela 4, do total da pauta exportadora de cada estado, parcela significativa dos itens de média-alta tecnologia era exportada para esse bloco econômico, no ano de 2000 - Rio Grande do Sul e São Paulo tiveram acréscimo desta categoria em 2010. Já o Rio de Janeiro, além de ter acentuada redução das exportações de alta tecnologia para este destino, acompanhou Minas Gerais quanto à queda das exportações de média-alta intensidade tecnológica. São Paulo, o principal responsável pela exportação de produtos de alta tecnologia, apresentou uma queda, passando de 23,96\%, em 2000, para 18,40\%, em 2010. Ao passo que Rio Grande do Sul, Rio de Janeiro e Minas Gerais reduziram as exportações de itens de baixa intensidade tecnológica para a UE, São Paulo aumentou a participação de produtos deste nível tecnológico ao longo do período. Já os produtos primários tiveram crescimento em importância na pauta exportadora gaúcha, mineira e carioca para este destino, enquanto que, para o Rio de Janeiro, a participação desta categoria passou de 7,51\%, em 2000, para 67,16\%, em 2010.

Tabela 4 - Participação de cada nível de intensidade tecnológica nas exportações dos estados selecionados para a União Europeia em \% - 2000/2010

\begin{tabular}{l|cc|cc|cc|cc}
\hline Intensidade Tecnológica & \multicolumn{9}{c|}{ Participação na pauta exportadora em \% } \\
\cline { 2 - 10 } & \multicolumn{2}{|c}{ RS } & \multicolumn{2}{c}{ SP } & \multicolumn{2}{c|}{ RJ } & \multicolumn{2}{c}{ MG } \\
\cline { 2 - 10 } Al ta tecnologia & $\mathbf{2 0 0 0}$ & $\mathbf{2 0 1 0}$ & $\mathbf{2 0 0 0}$ & $\mathbf{2 0 1 0}$ & $\mathbf{2 0 0 0}$ & $\mathbf{2 0 1 0}$ & $\mathbf{2 0 0 0}$ & $\mathbf{2 0 1 0}$ \\
Média-al ta tecnologia & 1,99 & 1,79 & 23,96 & 18,40 & 21,80 & 0,99 & 1,14 & 2,00 \\
Média-baixa tecnologia & 13,34 & 17,08 & 24,50 & 29,86 & 15,61 & 10,39 & 22,06 & 8,72 \\
Baixa tecnologia & 3,65 & 2,76 & 7,73 & 8,67 & 44,13 & 20,60 & 13,14 & 22,56 \\
Prod. Primários & 54,30 & 47,91 & 37,53 & 38,43 & 10,94 & 0,85 & 8,94 & 8,15 \\
\hline
\end{tabular}

Fonte: Exportações de MDIC/AliceWeb2. Intensidade tecnológica conforme OECD/ISIC revisão 3. Elaboração dos autores.

Se este estudo desagregasse a UE por países e comparasse com os demais destinos investigados, no ano de 2000, certamente os EUA estariam em primeira posição como destino das exportações brasileiras e dos estados. Entretanto, este país perdeu a importância como parceiro comercial nas trocas internacionais com o Brasil, sendo superado pela China, em 2010 (apenas as exportações de São Paulo não tinham a China como o principal destino). De acordo com a Tabela 5, São Paulo e Rio de Janeiro, que, do total de suas exportações aos EUA, remetiam consideráveis percentuais em 2000 (43,40\% e 13,33\% respectivamente), registram queda, tal como percebido para a UE. $O$ aumento das exportações totais de média-alta tecnologia verificado no Rio Grande do Sul e em São Paulo, entre 2000 e 2010, pode ser explicado pela variação dos produtos destinados aos EUA, pois houve consideráveis incrementos dentre o total remetido a este destino: 25,32 do Rio Grande do Sul e 16,11 pontos percentuais de São Paulo. Em igual modo ao cenário verificado para a UE, as exportações de baixa tecnologia do Rio Grande do Sul, do Rio de Janeiro e de Minas Gerais aos EUA tiveram queda no período, de forma que apenas São Paulo registrou acréscimo nesta categoria. Em relação aos produtos primários, todos os estados selecionados 
apresentaram acréscimo em suas exportações em detrimento de outros produtos com alguma intensidade tecnológica.

Tabela 5 - Participação de cada nível de intensidade tecnológica nas exportações dos estados selecionados para os Estados Unidos em \% - 2000/2010

\begin{tabular}{l|cc|cc|cc|cc}
\hline Intensidade Tecnológica & \multicolumn{9}{c|}{ Participação na pauta exportadora em \% } \\
\hline & \multicolumn{2}{|c|}{ RS } & \multicolumn{2}{c}{ SP } & \multicolumn{2}{c}{ RJ } & \multicolumn{2}{c}{ MG } \\
\cline { 2 - 10 } & $\mathbf{2 0 0 0}$ & $\mathbf{2 0 1 0}$ & $\mathbf{2 0 0 0}$ & $\mathbf{2 0 1 0}$ & $\mathbf{2 0 0 0}$ & $\mathbf{2 0 1 0}$ & $\mathbf{2 0 0 0}$ & $\mathbf{2 0 1 0}$ \\
Alta tecnologia & 0,79 & 1,37 & 43,40 & 15,11 & 13,33 & 0,20 & 1,29 & 1,04 \\
Média-alta tecnologia & 16,61 & 41,93 & 25,75 & 41,86 & 20,55 & 2,18 & 14,29 & 14,71 \\
Média-baixa tecnologia & 3,22 & 11,39 & 17,47 & 18,24 & 50,74 & 7,86 & 58,00 & 34,57 \\
Baixa tecnologia & 71,79 & 28,23 & 12,41 & 21,10 & 6,20 & 1,96 & 8,51 & 6,96 \\
Prod. Primários & 7,59 & 17,08 & 0,97 & 3,69 & 9,18 & 87,81 & 17,92 & 42,72 \\
\hline
\end{tabular}

Fonte: Exportações de MDIC/AliceWeb2. Intensidade tecnológica conforme ISIC revisão 3. Elaboração dos autores.

Ao analisar as exportações para o Mercosul, percebe-se grande diferenciação em relação aos demais destinos. Enquanto a pauta exportadora dos estados para EUA, UE e China apresentou queda da participação de produtos de alta e média-alta intensidade tecnológica e acréscimo de itens de baixa intensidade tecnológica e produtos primários, entre 2000 e 2010, conforme indica a Tabela, houve concentração das exportações ao bloco econômico de mercadorias de média-alta intensidade, com ascensão em todos os estados avaliados. Os principais itens exportados desta categoria foram os veículos e automóveis, bem como suas peças e seus acessórios. Tal concentração está associada à maior proteção deste setor no bloco econômico, protegido por altas tarifas de importação extrabloco, o que estimula o comércio intrabloco, especialmente do setor automotivo. Enquanto São Paulo, Rio de Janeiro e Minas Gerais reduziram a participação de produtos de média-baixa intensidade tecnológica, o Rio Grande do Sul mostrou tendência oposta, com aumento das exportações desta categoria em detrimento de produtos de baixa intensidade tecnológica. Com exceção de Minas Gerais, todos os demais estados tiveram incremento de produtos primários na pauta exportadora ao Mercosul, com maior variação ocorrendo no Rio de Janeiro, que, no período analisado, teve 9,06 pontos percentuais de acréscimo. São Paulo, que detinha o maior percentual de participação de produtos de alta tecnologia em ambos os períodos, reduziu a participação das exportações deste nível tecnológico de 19,87\%, em 2000, para 12,00\%, em 2010.

Tabela 6 - Participação de cada nível de intensidade tecnológica nas exportações dos estados selecionados para o Mercosul em \% - 2000/2010

\begin{tabular}{l|cc|cc|cc|cc}
\hline Intensidade Tecnológica & \multicolumn{9}{c}{ Participação na pauta exportadora em \% } \\
\hline & \multicolumn{2}{|c|}{ RS } & \multicolumn{2}{c}{ SP } & \multicolumn{2}{c}{ RJ } & \multicolumn{2}{c}{ MG } \\
\cline { 2 - 10 } & $\mathbf{2 0 0 0}$ & $\mathbf{2 0 1 0}$ & $\mathbf{2 0 0 0}$ & $\mathbf{2 0 1 0}$ & $\mathbf{2 0 0 0}$ & $\mathbf{2 0 1 0}$ & $\mathbf{2 0 0 0}$ & $\mathbf{2 0 1 0}$ \\
Alta tecnologia & 0,77 & 0,70 & 19,87 & 12,00 & 5,21 & 4,05 & 1,07 & 1,76 \\
Média-alta tecnologia & 47,70 & 54,55 & 48,25 & 66,21 & 35,14 & 60,44 & 40,84 & 61,64 \\
Média-baixa tecnologia & 10,27 & 22,05 & 14,95 & 13,62 & 46,59 & 20,32 & 29,47 & 25,57 \\
Baixa tecnologia & 38,21 & 15,81 & 16,60 & 7,55 & 9,68 & 2,75 & 11,35 & 3,82 \\
Prod. Primários & 3,05 & 6,90 & 0,33 & 0,62 & 3,37 & 12,43 & 17,27 & 7,20 \\
\hline
\end{tabular}

Fonte: Exportações de MDIC/AliceWeb2. Intensidade tecnológica conforme OECD/ISIC revisão 3. Elaboração dos autores. 
Em 2000, as exportações dos estados brasileiros para a China eram mais diversificadas em relação a 2010. Como mostra a Tabela 7, das exportações totais do Rio Grande do Sul a este destino, 13,80\% eram de média-alta tecnologia, enquanto que de São Paulo eram 25,26\% e do Rio de Janeiro chegavam a 10,43\%. Em 2010, as exportações desta categoria diminuíram a participação em todos os estados. De modo geral, o aumento da participação de produtos de baixa intensidade tecnológica e de produtos primários nas exportações à China foi notável -, de toda a pauta exportadora do Rio de Janeiro, em 2010, 98,67\% correspondiam apenas a exportações de commodities, enquanto que Minas Gerais exportava o equivalente a 88,15\% do total, em 2010. Afora o acréscimo da participação de produtos de alta tecnologia nas exportações de São Paulo e Rio Grande do Sul, todas as demais exportações de alta, média-alta e média-baixa intensidade tecnológica dos estados perderam posição para produtos com baixa intensidade tecnológica ou produtos primários.

Tabela 7 - Participação de cada nível de intensidade tecnológica nas exportações dos estados selecionados para a China, HK, Macau e Taiwan em \% - 2000/2010

\begin{tabular}{l|cc|cc|cc|cc}
\hline Intensidade Tecnológica & \multicolumn{7}{c|}{ Participação na pauta exportadora em \% } \\
\hline & \multicolumn{2}{|c|}{ RS } & \multicolumn{2}{c|}{ SP } & \multicolumn{2}{c|}{ RJ } & \multicolumn{2}{c}{ MG } \\
\cline { 2 - 10 } & $\mathbf{2 0 0 0}$ & $\mathbf{2 0 1 0}$ & $\mathbf{2 0 0 0}$ & $\mathbf{2 0 1 0}$ & $\mathbf{2 0 0 0}$ & $\mathbf{2 0 1 0}$ & $\mathbf{2 0 0 0}$ & $\mathbf{2 0 1 0}$ \\
Alta tecnol ogia & 0,71 & 0,85 & 14,71 & 19,13 & 3,94 & 0,10 & 1,29 & 0,19 \\
Média-al ta tecnologia & 13,80 & 3,51 & 25,26 & 13,92 & 10,43 & 0,81 & 1,48 & 0,18 \\
Média-baixa tecnologia & 1,16 & 0,10 & 13,74 & 7,65 & 18,65 & 0,40 & 33,58 & 7,37 \\
Baixa tecnologia & 28,78 & 27,24 & 43,32 & 47,97 & 5,36 & 0,03 & 6,88 & 4,12 \\
Prod. Primários & 55,55 & 68,29 & 2,98 & 11,33 & 61,62 & 98,67 & 56,77 & 88,15 \\
\hline
\end{tabular}

Fonte: Exportações de MDIC/AliceWeb2. Intensidade tecnológica conforme OECD/ISIC revisão 3. Elaboração dos autores.

Em síntese, no final de 2010, a principal participação na pauta exportadora dos estados de produtos de média-alta tecnologia era de exportações destinadas ao Mercosul, aos EUA e à UE. Os produtos de média-baixa intensidade tecnológica tiveram maiores participações, nas pautas exportadoras estaduais, quando destinados ao Mercosul e aos EUA, ao passo que os itens classificados como de baixa intensidade tecnológica tiveram maiores participações quando enviados à UE e China. Por fim, a China e a UE foram os destinos que detiveram as maiores participações de produtos primários nas pautas exportadoras estaduais, com exceção do Rio de Janeiro, que concentrou as exportações desta categoria também aos EUA. Dado ao aumento relativo das exportações estaduais para os parceiros comerciais que demandavam mais commodities, o processo de reprimarização da pauta exportadora brasileira também esteve presente nos principais estados exportadores.

\section{CONCLUSÕES}

Com exceção da crise financeira internacional deflagrada nos EUA em 2008, a qual afetou o Brasil e os estados selecionados em 2009, os demais anos analisados foram favoráveis às trocas internacionais, refletindo sobre a pauta exportadora brasileira, que mostrou um aumento no volume exportado de 366,3\% entre 2000 e 2010, principalmente devido ao reflexo do aumento dos preços das commodities ${ }^{12}$. Apesar do cenário de crescimento, os estados de São Paulo e do Rio Grande do Sul reduziram suas participações no total da pauta exportadora brasileira, enquanto Minas Gerais e Rio de Janeiro elevaram a sua participação quando comparados ao período inicial analisado.

${ }^{12}$ IMF. International Monetary Fund. Indices of Primary Commodity Prices, 2000-2011. 
Em relação ao conteúdo tecnológico das exportações do Brasil, entre 2000 e 2010, apesar do incremento em termos absolutos de todas as categorias, sobressaíram-se as exportações de produtos de baixa tecnologia e de produtos primários em detrimento das demais intensidades tecnológicas, que tiveram forte queda de participação na pauta exportadora do país. Portanto, a persistência da queda de participação dos produtos de alta e média-alta tecnologia em termos relativos indica a manutenção da reprimarização da pauta exportadora brasileira apontada por Gonçalves (2001), durante a década de 1990, percebida como consequência dos principais estados exportadores brasileiros, consolidando ao país a posição de especialização em commodities. Esse processo não seria, necessariamente, um problema, tal como ressalta Ribeiro (2009), pois a reprimarização deriva das atuais vantagens comparativas brasileiras - resultado dos investimentos e do aumento da produtividade média. Também, o Brasil seria uma economia com uma pauta exportadora com diversos produtos primários, não apenas dependente de um ou poucos itens. Contudo, a permanência desse cenário poderia levar a um processo de desindustrialização do país, caso mantida a apreciação cambial que reduz a competitividade da indústria brasileira. Além do câmbio, outros fatores contribuem para esse processo, tais como altos custos de transação, infraestrutura inadequada, problemas de logística, baixa taxa de investimento público e elevada carga tributária.

Quanto à evolução das exportações estaduais por intensidade tecnológica, Rio de Janeiro e Minas Gerais seguiram o comportamento brasileiro de elevação da participação de produtos primários em 66,25 e 17,22 pontos percentuais, respectivamente, entre 2000 e 2010. O Rio Grande do Sul teve semelhante desempenho, mas logrou incremento nas categorias de média-alta e média-baixa intensidade, o que pode ter contribuído para uma queda mais amena no agregado brasileiro nestas intensidades tecnológicas. Dos estados considerados, São Paulo detinha o maior nível de produtos com alta intensidade tecnológica, estando, em 2010, com participação de produtos high-tech de $12,27 \%$ no total de sua pauta, mesmo após 12,15 pontos percentuais de queda em comparação ao ano de 2000. Entretanto, também houve variação positiva dos produtos de baixa intensidade tecnológica de 23,76\%, em 2000, para 34,94\%, em 2010.

No que tange à intensidade tecnológica das exportações por destino, há diferenciações importantes. Das mercadorias exportadas ao Mercosul, todos os estados mostraram aumento na participação de itens de média-alta e média-baixa intensidade tecnológica. A China, por sua vez, teve suas importações dos estados concentradas em produtos de baixa tecnologia e em produtos primários. Os EUA têm participação mais bem-distribuída em vários itens de intensidade para todos os estados, apenas com concentração demasiada em produtos primários para o Rio de Janeiro.

Em suma, o comportamento de todos os estados selecionados, os quais respondiam por mais da metade das exportações do Brasil em ambos os períodos, demonstram, conjuntamente, a sua influência sobre a atual situação da economia brasileira, mesmo que em graus diferenciados. Além disso, a tendência de reprimarização da pauta de exportação dos estados selecionados, assim como ocorre com o país, também se deve ao aumento acima da média das exportações para a China. Uma limitação deste estudo refere-se à análise de apenas quatro estados brasileiros, embora eles representem mais de $50 \%$ das exportações do país, tanto em 2000 como em 2010. Assim, um futuro tema de pesquisa seria examinar se os demais estados brasileiros também mostram a mesma tendência observada no país e nos principais estados exportadores. Além disso, seria relevante averiguar mais detidamente os setores de alta e média intensidade tecnológica, que estão perdendo participação na pauta exportadora, a fim de identificar as principais causas desse processo. 


\section{REFERÊNCIAS}

ALICEWEB2. Sistema de Análise das Informações de Comércio Exterior via Internet da Secretaria de Comércio Exterior (SECEX), do Ministério do Desenvolvimento, Indústria e Comércio Exterior (MDIC). Brasil. Disponível em: <http://aliceweb2.mdic.gov.br/>.

ANJOS, Adriana Toledo Mendes dos; AZEVEDO, André Filipe Zago de; TERRA, Paulo Renato Soares. Um estudo empírico sobre as perspectivas de ampliação das relações comerciais entre Brasil e China. In: IV ENCONTRO DE ECONOMIA CATARINENSE, Santa Catarina, 2010. Anais eletrônicos... Santa Catarina: Universidade do Extremo Sul Catarinense, 2010. Disponível em:<http:// www.apec.unesc.net/IV_EEC/sessoes_ tematicas/Temas\%20 especiais/Um\%20 estudo\%20emp\%edrico\%20sobre\%20as\%20 perspectivas $\% 20$ de\%20amplia\%e7\%e3o\%20 das\%20rela\%e7\%f5es\%20 comerciais $\% 20$ entre\%20Brasil\%20e\%20China.pdf>. Acesso em: 13 jul. 2011.

BELLUZZO, L.G. 2002. Brasil: um desenvolvimento difícil. In: A.C. CASTRO (org.), Desenvolvimento em debate - Painéis do desenvolvimento brasileiro. Rio de Janeiro, Ed. Mauad e BNDES, vol. 1, p. 57-72.

BENDER, Siegfried. Conflitos e convergências na ALCA numa perspectiva de vantagens comparativas reveladas de países das Américas. Revista de Economia Aplicada, Ribeirão Preto, v. 10, n. 1, p. 111-135, jan./mar., 2006.

BRASIL. Ministério do Desenvolvimento, Indústria e Comércio Exterior (MDIC). Secretaria de Comércio Exterior (SECEX). Departamento de Negociações Internacionais. Tarifa Externa Comum (TEC) implantada pelo Decreto 1.343, de 23/12/94 e adaptação ao IV Emenda do Sistema Harmonizado pela Resolução CAMEX 43, de 22/12/2006. Disponível em: < http:// www.mdic.gov.br//sitio/interna/interna. php?area $=5 \&$ menu $=1848>$. Acesso em: 02 out. 2011.

CARVALHO, Maria Auxiliadora de; SILVA, César Roberto Leite da. Mudanças na pauta das exportações agrícolas brasileiras. Revista de Economia e Sociologia Rural, Brasília, v. 46, n. 1, p. 53-73, jan./mar. 2008.

CASTILHOS, Clarisse Chiappini; CARNEIRO, Gustavo Meira. Volta à competitividade espúria? In: XIII ENCONTRO NACIONAL DE ECONOMIA POLÍTICA, Paraíba, 2008. Anais eletrônicos... Paraíba: Sociedade Brasileira de Economia Política, 2008. Disponível em: $<$ http://www.sep.org.br/pt/artigo_list. php?id=3 > . Acesso em: 06 nov. 2011.

COUTINHO, Luciano; HIRATUKA, Célio; SABBATINI, Rodrigo. O desafio da construção de uma inserção externa dinamizadora. In: SEMINÁRIO BRASIL EM DESENVOLVIMENTO, Rio de Janeiro, 2003. Anais eletrônicos... Rio de Janeiro: Universidade Federal do Rio de Janeiro, 2003. Disponível em: <http://www. ie.ufrj.br/desenvolvimento/pdfs/o_desafio_ da_construcao_de_uma_insercao_externa_ dinamizadora.pdf $>$. Acesso em: 05 ago. 2011.

CRUZ, Marcio José Vargas; NAKABASHI, Luciano; PORCILE, Gabriel; SCATOLIN, Fábio Dória. Uma análise do impacto da composição ocupacional sobre o crescimento da economia brasileira. Revista da Anpec, Rio de Janeiro, v. 8, n. 4, dez. 2007.

DENARDIN, Élio Sérgio; MURINI, Lisandra Taschetto; DUARTE, Tatiane Lopes; MEDEIROS, Flaviani Souto Bolzan; DILL, Lourdes Maria Staudt; DENARDIN, Elisandra Freitas. Os tipos de inovações implementadas nos empreendimentos de economia solidária do projeto esperança/cooesperança de Santa Maria - RS. Revista de Administração da UFSM, Santa Maria, v. 5, p. 651-666, 2012.

ERBER, Fabio Stefano. O padrão de desenvolvimento industrial e tecnológico e o futuro da indústria brasileira. Revista de 
Economia Contemporânea, Rio de Janeiro, v. 5, 2001. Edição Especial.

FEE. Fundação de Economia e Estatística. Nota metodológica. Centro de Informações Estatísticas/Núcleo de Produtos Estatísticos. Disponível em: <http://www.fee.tche. $\mathrm{br} / \mathrm{sitefee/download/exportacoes/nota-}$ metodologica.pdf>. Acesso em: 02 out. 2011.

FERNÁNDEZ-JARDÓN, Carlos Maria. Determinantes de la capacidad de innovación en Pymes regionales. Revista de Administração da UFSM, Santa Maria, v. 5, p. 749-766, 2012.

FLIGENSPAN, Flavio Benevett; CUNHA, André Moreira; LÉLIS, Marcos Tadeu Caputi. O desempenho da indústria de transformação nos anos 2000. In: 39 ENCONTRO NACIONAL DE ECONOMIA, Paraná, 2011. Anais eletrônicos... Foz do Iguaçu, Paraná, 2011. Disponível em: < http://www.anpec.org.br/encontro_2011. htm>. Acesso em: 22 dez. 2011.

FURTADO, André (Coord.). Capacitação Tecnológica, competitividade e política industrial: uma abordagem setorial e por empresas líderes. IPEA, Texto para Discussão n. 348, Brasília, 1994

FURTADO, André Tosi; CARVALHO, Ruy de Quadros. Padrões de intensidade tecnológica da indústria brasileiras: um estudo comparativo com os países centrais. São Paulo em Perspectiva, São Paulo, v. 19, n. 1, jan./ mar., p. 70-84, 2005.

GONÇALVES, Reinaldo. Competitividade internacional e integração regional: a hipótese da inserção regressiva. Revista de Economia Contemporânea, Rio de Janeiro, v. 5, 2001. Edição Especial.

GONÇALVES, R.; BAUMANN, R.; PRADO, L.C.D.; CANUTO, O. A nova economia internacional: uma perspectiva brasileira. Rio de Janeiro. Campus, 1998.

GUIMARÃES, Edson P. Competitividade internacional: conceitos e medidas. Estudos em Comércio Exterior, Rio de Janeiro, v. I, n. 3, jul./dez., 1997.

HIDALGO, Álvaro Barrantes; MATA, Daniel F. P. Gonçalves da. Inserção das regiões brasileiras no comércio internacional: os casos da Região Nordeste e do Estado de Pernambuco. Ensaios FEE, v. 26, Rio Grande do Sul, 2005.

IBGE. Instituto Brasileiro de Geografia e Estatística. Tabela de Correspondência. Comissão Nacional de Classificação. Classificações estatísticas e a comissão nacional de classificação (CONCLA). Brasil. Disponível em: <http://www.ibge.gov.br/ concla/cl_corresp.php?sl=3>.

ILHA, Adayr da Silva; DORNELLES, Juliana Pavan; WEGNER, Rubia Cristina. Inserção internacional do Rio Grande do Sul: vantagens comparativas reveladas e comércio intraindústria. Perspectiva Econômica, Rio Grande do Sul, v. 5, 2009.

IMF. International Monetary Fund. Indices of Primary Commodity Prices, 2000 2011. Commodities Team of the Research Department. Disponível em: <http://www.imf. org/external/np/res/commod/index.aspx>. Acesso em: 30 nov. 2011

LALL, S. The Technological Structure and Performance of Developing Country Manufactured Exports, 1985-1998. QEH Working Paper Series, WP n. 44, Oxford: junho/2000.

LEITZKE, Alexander Nunes. As exportações dos estados da região sul do Brasil por intensidade tecnológica entre 1996 e 2007. 2008. 119 f. Dissertação (Mestrado em Economia) Programa de Pós-Graduação em Economia. Universidade do Vale do Rio dos Sinos, São Leopoldo, RS, 2008.

MARCONI. Nelson. Existe doença holandesa no Brasil? In: XIII ENCONTRO NACIONAL DE ECONOMIA POLÍTICA, Paraíba, 2008. Anais eletrônicos... Paraíba: Sociedade Brasileira 
de Economia Política, 2008. Disponível em: <http://www.sep.org.br/pt/artigo_list. php?id=3 > . Acesso em: 05 nov. 2011.

MARKWALD, Ricardo. Intensidade Tecnológica e Dinamismo das Exportações Brasileiras. Revista Brasileira de Comércio Exterior, Rio de Janeiro, n. 79, p.3-11, 2004.

NASCIMENTO, Carlos Alves; CARDOZO, Soraia Aparecida; NASCIMENTO, Katiucy Lemes. O sentido da reprimarização da pauta exportadora: uma interpretação à luz de Celso Furtado, Caio Prado Jr. e Francisco de Oliveira. In: XLVI CONGRESSO DA SOCIEDADE BRASILEIRA DE ECONOMIA, ADMINISTRAÇÃO E SOCIOLOGIA RURAL, Acre, 2008. Anais eletrônicos... Acre: Faculdade da Amazônia Ocidental, 2008. Disponível em: <http://www. sober.org.br/palestra/9/326.pdf>. Acesso em: 09 nov. 2011.

NASSIF, André. Há evidências de desindustrialização no Brasil? Revista de Economia Política. São Paulo, v. 28, n. 1, p. 7296, jan./mar. 2008.

OECD. Organisation for Economic Co-operation and Development. ISIC Rev. 3 Technology Intensity Definition. STAN Indicators. Directorate for Science, Technology and Industry. Economic Analysis and Statistics Division. França, 2003. Disponível em: <http://www.oecd.org/ dataoecd/43/41/48350231.pdf>.

OREIRO, José Luis; FEIJÓ, Carmem A. Desindustrialização: conceituação, causas, efeitos e o caso brasileiro. Revista de Economia Política. São Paulo, v. 30, n. 2, p. 219-232, abr./ jun. 2010.

PEREIRA, Wellington; FURTADO, João; PORCILE, Gabriel. Exame da competitividade industrial através do conteúdo tecnológico do comércio internacional brasileiro. In: XXXV ENCONTRO NACIONAL DE ECONOMIA, Pernambuco, 2007. Disponível em: < http://www.anpec.org.br/ encontro_2007.htm>. Acesso em: 10 ago. 2011.
RIBEIRO, Fernando. "Reprimarização" das exportações: onde está o problema? Revista Brasileira de Comércio Exterior, Rio de Janeiro, n. 99, p. 2-3, jun. 2009.

ROWTHORN, Robert; RAMASWAMY, Ramana. Growth, trade, and deindustrialization. IMF Staff Papers, v. 46, n. 1, 1999.

SILVEIRA, Vanessa Monks da; ANTUNES, Graziela Mota; DIAS, Marcelo Fernandes Pacheco. Inovação em sistemas de produção de arroz orgânico no Rio Grande do Sul. Revista de Administração da UFSM, Santa Maria, v. 5, p. 715-728, 2012.

SOARES, Cristiane; MUTTER, Anderson; OREIRO, José Luis; MAGALHÃES, Rodrigo. Uma análise empírica dos determinantes do processo de desindustrialização da economia brasileira no período 1996-2008. In: 39o ENCONTRO NACIONAL DE ECONOMIA, Paraná, 2011. Anais eletrônicos... Foz do Iguaçu, Paraná, 2011. Disponível em: < http://www. anpec.org.br/encontro_2011.htm>. Acesso em: 22 dez. 2011.

TEPASSÊ, Ângela Cristina; CARVALHO, Carlos Eduardo. Efeitos da ascensão da China sobre a competitividade das exportações brasileiras para EUA, Argentina e México. In: XV ENCONTRO NACIONAL DE ECONOMIA POLÍTICA, Maranhão, 2010. Anais eletrônicos... Maranhão: Sociedade Brasileira de Economia Política, 2010. Disponível em: $<$ http://www. sep.org.br/pt/artigo_list.php?id=5>. Acesso em: 10 out. 2011.

WTO. World Trade Organization. International Trade Statistics 2011. Appendix: Historical trends. 